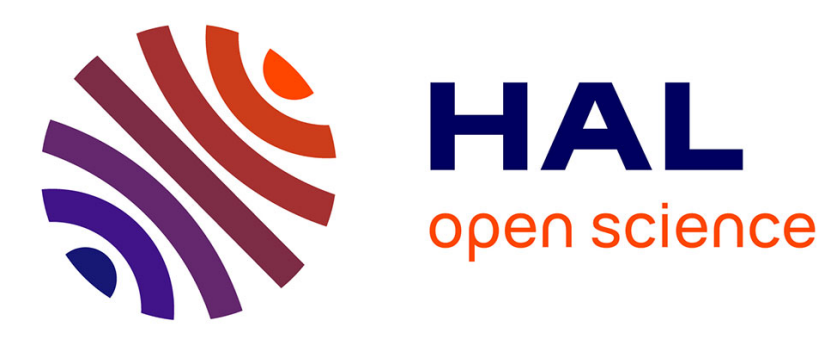

\title{
Assessing pupils' skills: Implications for research in education
}

Sophie Morlaix

\section{To cite this version:}

Sophie Morlaix. Assessing pupils' skills : Implications for research in education. Journal of Curriculum Studies, 2010, 42 (3), pp.22. 10.1080/00220272.2010.484507 . halshs-00431580

\section{HAL Id: halshs-00431580 \\ https://shs.hal.science/halshs-00431580}

Submitted on 20 Feb 2018

HAL is a multi-disciplinary open access archive for the deposit and dissemination of scientific research documents, whether they are published or not. The documents may come from teaching and research institutions in France or abroad, or from public or private research centers.
L'archive ouverte pluridisciplinaire HAL, est destinée au dépôt et à la diffusion de documents scientifiques de niveau recherche, publiés ou non, émanant des établissements d'enseignement et de recherche français ou étrangers, des laboratoires publics ou privés. 
Assessing pupils’ skills: Implications for research in education

\author{
Sophie Morlaix \\ University of Burgundy - IREDU \\ Pôle AAFE \\ Esplanade Erasme, BP 26513, DIJON, 21065 FRANCE
}

Published in Journal of Curriculum Studies, Taylor \& Francis (Routledge), 2010, 42, pp.22 doi : $\underline{10.1080 / 00220272.2010 .484507}$

\begin{abstract}
The object of this article is the structure and evolution of skills developed by pupils at primary level. Starting from an analysis of the panel data provided by the French Ministry of Education, the main object of this paper is an original measurement of skills using structural models. The findings of this research raise two complementary issues. The first issue concerns the cross-curricular nature of skills suggesting a logic of disciplinary interdependence. The acquisition of a skill may be strongly correlated to the acquisition of other skills belonging to the same subject area or to other subject areas. The notion of a set of skills is used to account for the connections between the different aspects of acquired skills. The second issue concerns the evolution of skills over time. Here the aim will be to identify the kinds of skills that are the most predictive of subsequent educational success. This issue is highly relevant for educational policy-making. It is hoped that the results presented in this paper will improve our understanding of the ways in which schools might provide pupils with the best chances of success in the earliest stages of their educational career.
\end{abstract}

Key Words: structure and evolution of skills, structural models, key skills.

\title{
On the difficulty of defining the concept of skill
}

At a time when the new mission entrusted to schools increasingly resembles a check-list of skills that pupils need to acquire, the introduction by the French parliament of the notion of a 'common core of knowledge and skills' in 2005 is likewise indicative of a general tendency to emphasize and promote the acquisition of skills. For the Haut Conseil en Education (High Council for Education), the notion of a common core signals the transition from a conception of education centred around subject knowledge to an educational approach defined by and aimed at producing verifiable skills in specific situations and tasks. Yet for the many actors involved in education (teachers, parents, pupils, etc.), the introduction of the concept in school syllabi raises many questions about the very definition of a skill, a notion that is so difficult to define that one observer has described it as 'the conceptual equivalent of Ali Baba’s cave’ (translated from Crahay, 2006). 
For some, the concept of 'skill' refers to the capacity to use the triptych knowledge - know-how - relational competence (translated from Stroobants, 1998). However, other observers, including Le Boterf (1998), have argued that this distinction is not enough to define the concept of skill. By their conception, a skill is to be defined more specifically as a 'recognized ability for appropriate response' or as a 'validated ability for appropriate response'. A skill may also be defined as 'an ability to use knowledge and qualities to deal with a given problem' (translated from Mandon, 1990) or as 'the capacity to act efficiently in a given situation' (translated from Perrenoud, 1995). For Allal (1999), the notion of skill implies three characteristics: a skill includes several interconnected items of knowledge, is applicable to a range of situations, and is directed towards a specific purpose. In 2006, the definition chosen by the Haut Conseil en Education described a skill as 'a combination of knowledge, aptitudes and attitudes'.

Because the concept has many different facets, the task of rendering it operative is a particularly challenging one. Within the current educational system, a wide range of methods are used to assess the skills acquired by pupils. Although they have neither the same status (local, national, international tests) nor the same purpose (some are used for individual ends, such as identifying pupils' weaknesses; others are designed for a more global purpose, for instance to regulate the educational system), their common object is to provide a means of assessing the skills effectively developed by pupils. They make take the form of marks attributed by teachers or of grades obtained in large-scale national or international surveys. Yet whether it is done locally by teachers or on a more systematic basis at a national or international level, the assessment of acquired skills is limited by a number of factors.

The assessment of skills at a local level by teachers is subject to biases and errors of judgement resulting from the use of academic and non-academic background data (records of a pupil's educational level, past assessments and marks...). Other factors such as the personal character of examiners or pupils may also have an impact on teachers' perception and marking. These include social origins (De Landsheere, 1979), physical appearance or pupil gender (Nias \& Wilson, 1970; De Landsheere, 1992; Duru-Bellat, 1995), which are all liable to condition an examiner's behaviour. Teachers' assessments of skills may also be interpreted as arising from a tacit contract, a kind of informal arrangement or makeshift affair (Merle 1996, Perrenoud 1995) defined by a teacher on an individual basis with every pupil. Thus, while marking may be likened to an informal arrangement serving to modulate the educational order, teacher-pupil relations and the transmission of knowledge or learning rhythms, it is also liable to be heavily influenced by a teacher's own personal history and by the various connotations which a teacher tends to associate with the activity of marking (value judgements, support, sanctions, rewards...). By this conception, the process of assessment depends on a triple relation (Leclerq and al., 2004) between the teacher and her pupils, the teacher and her personality, and the teacher and external constraints (at 
the level of the classroom, school or system).

Other types of assessment, diagnosis and appraisal are used at the national or international level. At the national level, the diagnostic assessments which the Direction de l'Évaluation et la Prospective (Direction of Prospective and Assessment) introduced in 1989 are designed 'to enable the observation of skills and to assess the achievements and potential difficulties faced by every pupil considered individually at a given moment in their educational career. They provide teachers with potential indicators used to identify typical mistakes made by pupils in learning...' (translated from Ministry of Education, 2002). The purpose of national tests is to provide teachers with standard methods for the assessment of skills developed by pupils. Although diagnosis remains the primary focus, these assessments may also be used as guidelines since they provide an objective account of the standards reached by pupils at different (national, regional, local) levels. However, because it relies on an $a$ priori evaluation, the institutional definition of skills used in national tests is somewhat arbitrary. It implies furthermore a static approach since it is limited to a categorization by subject area and discipline. To this extent, it does not help to take account of the interdependent acquisition of skills.

International tests use other methods for the assessment of skills. The last few decades have seen an increasing number of large-scale international surveys designed to assess and compare the standards of different educational systems. Every three years since 2000, PISA (Programme for International Student Assessment) measures and compares the basic skills acquired by 15-year old pupils in three different areas: written expression, mathematics and science. One of the originalities of PISA is the assessment of knowledge and practical skills essential in everyday life at the end of compulsory education. Pupils are assessed not on their knowledge but on their capacity to use and apply that knowledge in a wide variety of practical situations. The aim of PISA is to assess the acquisition of abilities that are deemed to be essential in adult life. However, a number of criticisms frequently levelled at the capacity of largescale international surveys to assess pupils' skills also apply in the case of PISA. These include the objectives that 15-year old pupils are expected to reach, which differ from one country to the next, since PISA does not refer to knowledge acquired within educational curricula but to skills that may be of use in a later work context. These limitations present a serious challenge to PISA's artificial cross-national convergence of educational objectives coupled with its utilitarian vision of education (which tends to overlook French and broader European specificities).

There has been significant progress in the development of international comparative analyses, and the models currently used for assessing skills in international surveys have become considerably more sophisticated. However, their validity depends on conditions that are not necessarily invariably present, and it is impossible to guarantee 
that the results of these inquiries will not be distorted by a range of biases and prejudices, especially given that the proposed extension of the same programs, conceived as applying universally, will only serve to widen the range of development standards, cultures and languages.

Whether it be at the local level in the classroom or in schools, or at a national or international level, the assessment of skills acquired by pupils is therefore a task fraught with difficulties. Indeed, it is widely held that there is no single 'true' method for assessing pupils' skills that rules out even the slightest margin of error, even if considerable efforts are made to ensure that the objectives of educational programs are effectively operational. The approach to the issue from the perspective of skills such as the concept is defined in international surveys like PISA focuses more on behaviour or skills than on knowledge (Duru-Bellat, Mons \& Suchaut, 2004). But it is important to bear in mind that these skills are primarily constructs. As Vrignaud observes (2006), 'the process of validation of assessments in psychometry notably relies on the principle according to which every assessment is a construct'. Skills cannot be isolated from the way in which such constructs are made to operate. The assessment of skills has neither the simplicity, the robustness nor the universality that are characteristic of the metric system. In psychometry, an assessment is construed as a construct that is the product of political or methodological choices, defined by Reuchlin (1992) as an 'operational notion'. Certain methods have subsequently been developed in edumetrics to test the suitability of methods of measurement for the observed data.

\section{The empirical measurement of skills}

There are several methodological resources used in current educational research for the assessment of knowledge and skills. The three most widely used models are the classical theory of tests, the models of response to items (MRI), and structural models. Because the task of understanding and assessing the concept of skill is a multifaceted and complex process, the present research relied more specifically on the use of the third model. Structural models allow for a varied use of the concept of skill based on an empirical approach. They are used in a variety of areas (psychology, sociology, economics, etc.) and rely on methods of data analysis such as factorial analysis, multiple regression analysis and multiple equation models (Bacher, 1987). Structural models have the advantage of helping to account for a far more complex reality than the kinds of analyses provided by traditional regressions. They integrate two dimensions: a model of confirmatory factorial analysis indicating how latent variables are measured by observed variables, and a model of simultaneous equations specifying relations between latent variables ${ }^{11}$. I recently submitted the hypothesis that the skills

\footnotetext{
${ }^{1}$ In the 1970s, a group of researchers (Jöreskog \& Van Thillo, 1973; Jöreskog \& Sörbom, 1982) conceived and developed a software application known as LISREL (Linear Structural Relations) that
} 
developed by pupils are latent concepts that could not be adequately defined $a$ priori (Morlaix, 2007). The use of structural models leads to the emergence of latent dimensions (skills) based on existing correlations between several indicators. Starting from national tests, I posited that every mark obtained in the various items composing the tests might reasonably serve as a reliable indication of an acquired skill. By highlighting connections between indicators, my aim is to make the concept of skill fully operative. These models should therefore help to go beyond the a priori definition of skills commonly used in national and international tests, and to redefine skills a posteriori based on the items used in national tests to further our understanding of the construction and dynamics of learning.

My research focused on the panels of the French Ministry of Education (1997 panel, 9858 pupils for whom the results of an assessment of skills in national tests at the start of $C P$ in 1997, the start of CE2 in 1999 and the start of 6ème in 2002 were available, Ministry of Education, 1998). The methodology used for this research was founded on an analysis of the connections between the skills developed by pupils at three different stages in their primary educational career: first year $(C P)$, the start of their third year (CE2) and the first year of secondary education (6ème). The main body of work involved several phases. The object of phase one was to identify skills empirically by observing the statistical connections between the various items making up the tests. Phase two isolated the skills that were the most predictive of the average standard of the skills acquired in each of the three periods under investigation. Phase three aimed to bring these skills together in a longitudinal structure to gain a better understanding of how pupils' skills change over the course of the five years spent at primary school. The following example provides a useful illustration of the methodological approach adopted as a result of using structural models. In 1999, in the assessments of pupils at CE2 level carried out by the French Ministry of Education, seven categories of skills were initially defined by the designers of the tests: comprehension (41 items), language tools (40 items), production of written work (10 items) in French; geometry (17 items), measurements (32 items), numbers (32 items) and problem-solving (9 items) in Maths. The 91 items in French were spread across 18 exercises, and the 90 items in maths across 27 exercises. My approach therefore focused not on the skills defined initially by the designers of the national tests but on an a posteriori redefinition of skills based on the connections between different items. The analysis based on items had a dual purpose: to provide statistical tests of the relevance of the nomenclature of skills established by the designers of the tests and to identify new skills based on associations of items. From a practical point of view, this approach enables the use of a

enables the analysis of structural models in the social sciences and which subsequently generated other applications such as AMOS, EQS, LISCOMP, MPLUS, etc. LISREL compares two series of values in variables: the theoretical values implied by the model with which it is provided and the observed values. Calculations using LISREL involve two distinct phases: the use of PRELIS (a pre-processor of LISREL) that calculates a matrix of observed correlations providing input for the second phase of calculation where it is compared with the matrix of theoretical correlations 
scale of a common measurement since all the items are subject to the same standards of assessment: 0 for an incorrect answer, 1 for a correct answer.

Some exercises may be perceived as highly cohesive to the extent that the items that compose them tend to measure the same object (strong correlations), while others are composed of markedly more independent items. But while it may help to avoid some pitfalls, an analysis based on a scale of items also presents a number of drawbacks. The first such drawback is the high number of correlations calculated solely by reference to national tests taken at a specific level such as CE2 (14 535 correlations), which, from a strictly technical point of view, complicates the possibility of analysis and requires a selection of items. The second drawback relates to the low value of correlation coefficients if items are used as the analytical reference, which raises some doubts about the robustness of the observed relations. Since it is only at the level of items that the dynamics of learning can be properly accounted for, the item still remains the most relevant focus for the specific purposes of this research. The existence of cross-curricular skills appears to indicate that the process by which pupils develop skills tends to reach beyond established disciplinary boundaries, and beyond broad categories of disciplines or skills such as they are defined in national tests. For the purposes of structuring the analysis of connections between items, I defined groups of strongly correlated items; some of these groups involved a high number of correlations, while others only involved two or three correlations that could not be connected with other groups. By way of illustrating this approach, table 1 presents one such group of items (in this case eight items connected by nine bivariate correlations).

\begin{tabular}{l|l}
\hline Correlations & \multicolumn{1}{c}{ Brief description of items } \\
\hline F67/F62 & $\begin{array}{l}\text { Prepared dictation of a sentence: correct spelling of the word 'play' } \\
\text { (jouent)/Prepared dictation of a sentence: correct spelling of the word } \\
\text { 'during' } \\
\text { (pendant). }\end{array}$ \\
\hline F67/F60 & $\begin{array}{l}\text { Prepared dictation of a sentence: correct spelling of the word 'play' } \\
\text { (jouent)/Correct punctuation in a piece of written work (including } \\
\text { capitals and full stops). }\end{array}$ \\
\hline F67/F64 & $\begin{array}{l}\text { Prepared dictation of a sentence: correct spelling of the word } \\
\text { 'play' (jouent)/Prepared dictation of a sentence: correct spelling of } \\
\text { the word 'boys' (garçons). }\end{array}$ \\
\hline F67/F66 & $\begin{array}{l}\text { Prepared dictation of a sentence: correct spelling of the word 'play' } \\
\text { (jouent)/Prepared dictation of a sentence: correct spelling of the } \\
\text { word 'girls' (filles). }\end{array}$ \\
\hline F67/F63 & $\begin{array}{l}\text { Prepared dictation of a sentence: correct spelling of the word 'play' } \\
\text { (jouent)/Prepared dictation of a sentence: correct spelling of the word } \\
\text { 'playtime' (récréation). }\end{array}$ \\
\hline
\end{tabular}




\begin{tabular}{l|l}
\hline F67/F12 & $\begin{array}{l}\text { Prepared dictation of a sentence: correct spelling of the word 'play' } \\
\text { (jouent)/Identify kinds of writing in a range of extracts drawn } \\
\text { from different books. }\end{array}$ \\
\hline F67/F16 & $\begin{array}{l}\text { Prepared dictation of a sentence: correct spelling of the word 'play' } \\
\text { (jouent)/Answer questions about a text. }\end{array}$ \\
\hline F64/F62 & $\begin{array}{l}\text { Prepared dictation of a sentence: correct spelling of the word 'boys' } \\
\text { (garçons)/Prepared dictation of a sentence: correct spelling of the } \\
\text { word 'during' (pendant). }\end{array}$ \\
\hline F63/F62 & $\begin{array}{l}\text { Prepared dictation of a sentence: correct spelling of the word } \\
\text { 'playtime' } \\
\text { (récréation)/Prepared dictation of a sentence: correct spelling of } \\
\text { the word }\end{array}$ \\
\hline
\end{tabular}

Table 1: An illustration of a group of items based on correlations ${ }^{2}$ (CE2 assessment, 1999).

Among the 8 items in French, 5 related to the same exercise (62, 63, 64, 66, 67) and were designed to assess the same skill, i.e. the ability to 'write commonly used words, short sentences and short texts beneath the dictation'. In this particular exercise, pupils were asked to write down the following sentence read out by the teacher: 'During playtime, boys and girls play marbles'. The sentence had previously been written on the board and pupils were required to memorize the spelling of the words. The sentence was then erased and pupils were given a different exercise to work on, and it was only after this exercise had been completed that the sentence became the object of a dictation. Success in this exercise depends on several factors: spelling skills, an ability to recall the spelling of words from memory and, to a certain extent, an ability for sustained concentration. Item 60 is assumed to indicate the acquisition of the ability to 'copy out a word, sentence, text...'. This item is part of an exercise requiring pupils to copy out sentences drawn from a short text presented in the form of a constellation (the sentences are written in balloons and connected by an arrow to a picture illustrating the theme of the text) and to re-organize them in a more conventional form (a text divided into paragraphs). Item 60 assessed only one aspect of pupils' work: the use of correct punctuation (capitals and full stops). Item 12 was part of an exercise that required pupils to identify types of writing from a range of extracts drawn from different sources (poetry, dictionary, recipe book...). The targeted skill was the ability to 'distinguish different texts using indications found outside the text'. Finally, the object of item 16 was the ability 'to understand a text and to demonstrate adequate comprehension'. Pupils were given a text and were required to answer questions about it. In item 16, pupils were asked to circle 3 correct answers in a list of 6 possible answers.

In the analytical approach adopted here, the groupings of strongly correlated items

\footnotetext{
${ }^{2}$ The 'correlations' column indicates relations between items; for example, 'F67/F62' translates the correlation between items 67 and 62 in French.
} 
indicate the acquisition of one or several skills. Note that in national tests the 8 items correspond to 4 distinct skills. The next step involved the analysis of statistical connections within groups of items to highlight latent variables that may be interpreted as skills. The initial phase of the analysis consisted of a study of every set of correlation between the different items (29 sets of correlations). The aim was to provide a statistical test of the relevance of the sets of correlations between items belonging to the same group. I used a statistical method based on the existence of latent variables (LISREL analysis), which helps to identify for every group of items one or several skills accounting for the observed correlations. The aim therefore was either to validate every set of relation by identifying a skill summarizing all the correlations under study, or to suggest a new means of organizing connections between items by identifying several skills for the same relational set.

The LISREL method involves several stages (Aish-Van Vaerenbergh, 1997) since the software used helps to assess two types of measurement models. The first model concerns measurements that establish connections between latent variables (assumed skills) and their indicators (items). The second model is the structural model that determines connections between different latent variables. The measurement model is commonly illustrated with a diagram in which the latent variables are symbolized by ellipses and the observed variables (or indicators of latent variables) are represented in the form of rectangles. Continuous arrows represent the intensity of the relations that connect every indicator (or item) with the latent variable (or skill); a regression coefficient (and its degree of significativity) for every indicator provides an indication of the validity of the model (Morlaix, 2002). LISREL also helps to assess the reliability of the model by identifying errors of measurement on every indicator (represented by dotted arrows in the figure). It is therefore possible to establish whether the indicators retained are sufficiently 'robust' to measure the latent variable.

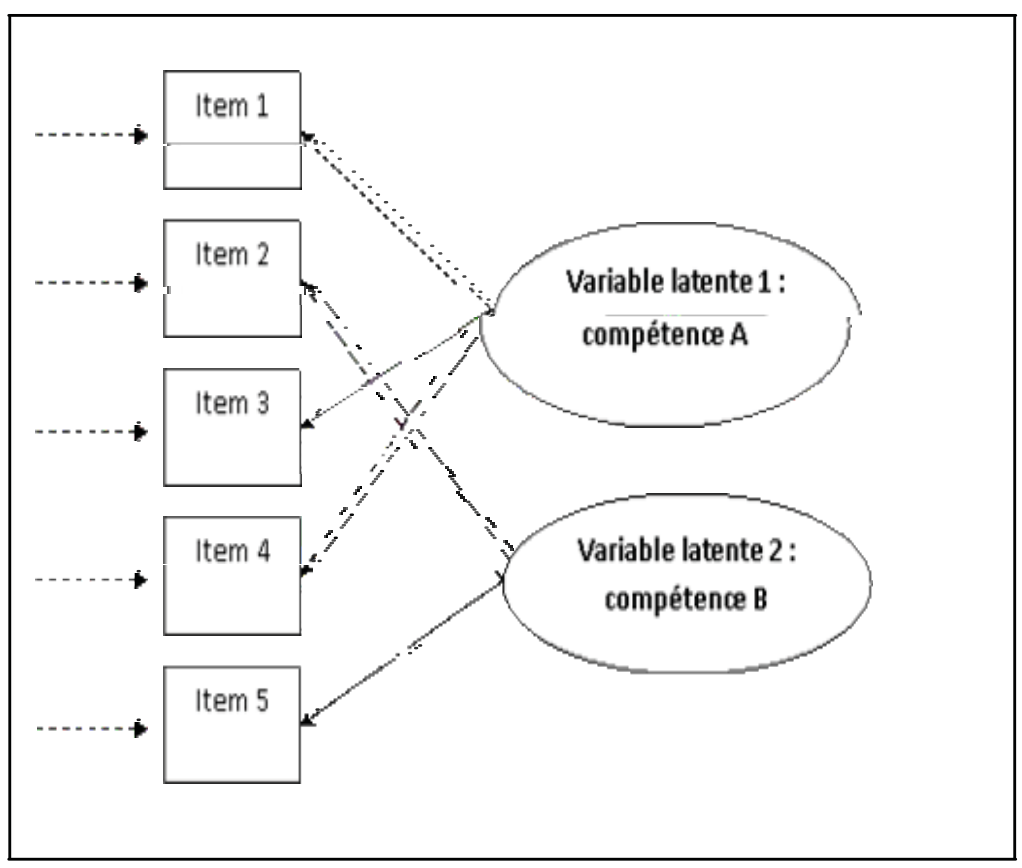


Figure 1: Model for measurements between two latent variables and their corresponding indicators. Latent variable 1: skill A.

Latent variable 2: skill B.

Measurement models were estimated for every group of items; the analysis of the group of items referred to above will provide an illustration of this approach. The first step consists in defining a latent variable indicating the connections between different items.

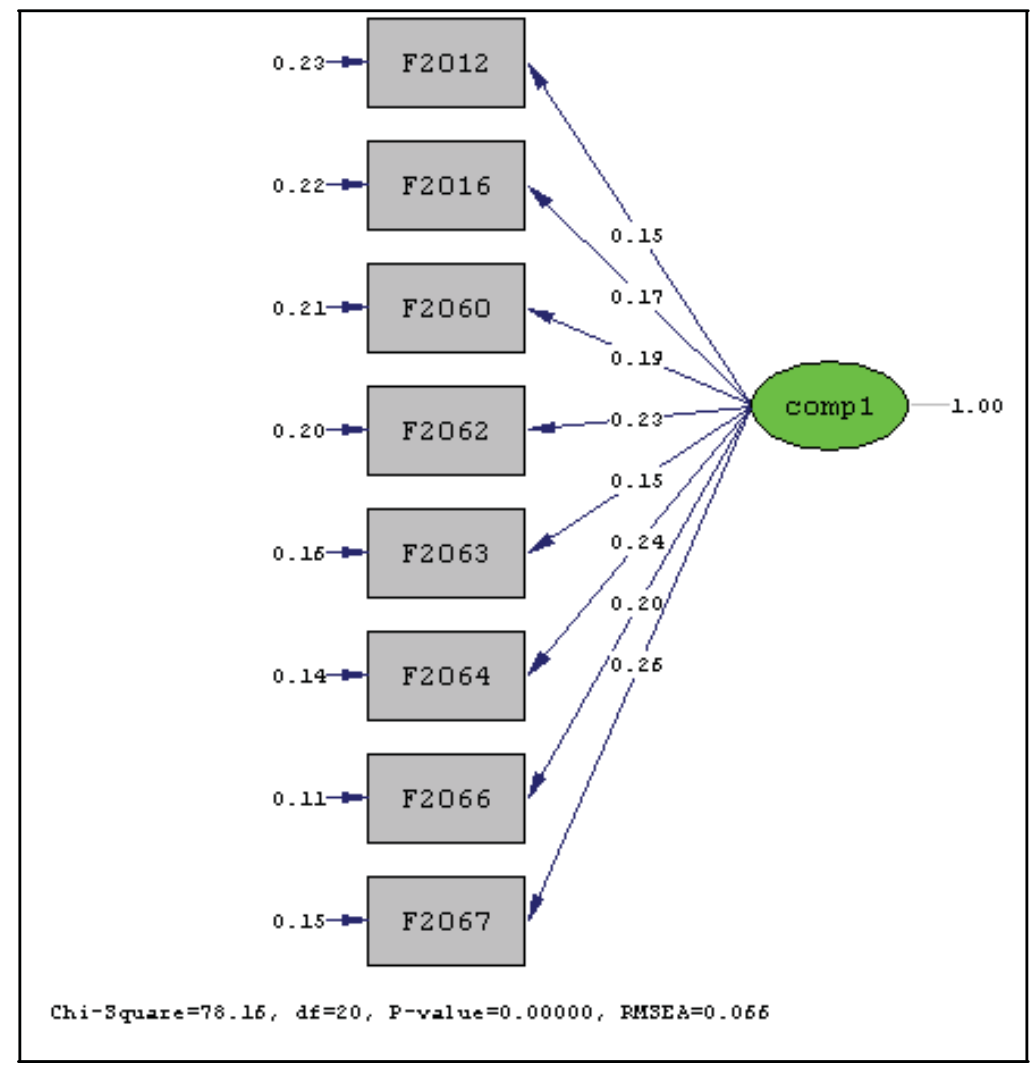

Figure 2: Initial model for the measurement of a skill based on existing correlations between items.

In Figure 2, the arrows indicate the regression coefficients between every item and the latent variable (comp1). The values of the coefficients provide information about the capacity of an item to indicate the latent variable, which is again designed to translate a skill. The latent variable is the most predictive of item 67 (coefficient: +0.26 ). Other statistical data provided by LISREL indicates that item 67 accounts for $31 \%$ of the variance of the latent variable. The statistical data provided by LISREL (Khi ${ }^{2}, \mathrm{P}$. Value and the residue) suggests that this initial measurement model could be significantly improved. The software application suggests that a new latent variable could be introduced into the analysis by isolating items 64 and 66 . 
A model using two latent variables was assessed on the basis of this new data. In this instance, the first variable was determined by items 12, 16, 60, 62, 63 and 67 ('comp1' in the figure), the second by items 64 and 66 ('comp2'). The statistical indicators of the new model are far more reliable (significant decrease of $\mathrm{Khi}^{2}$, increase of P. Value, decrease of the R.M.S.E.A.) and the software provides only one variable to improve the statistical quality of the representation. The figure below illustrates the new relations between the items and the two latent variables.

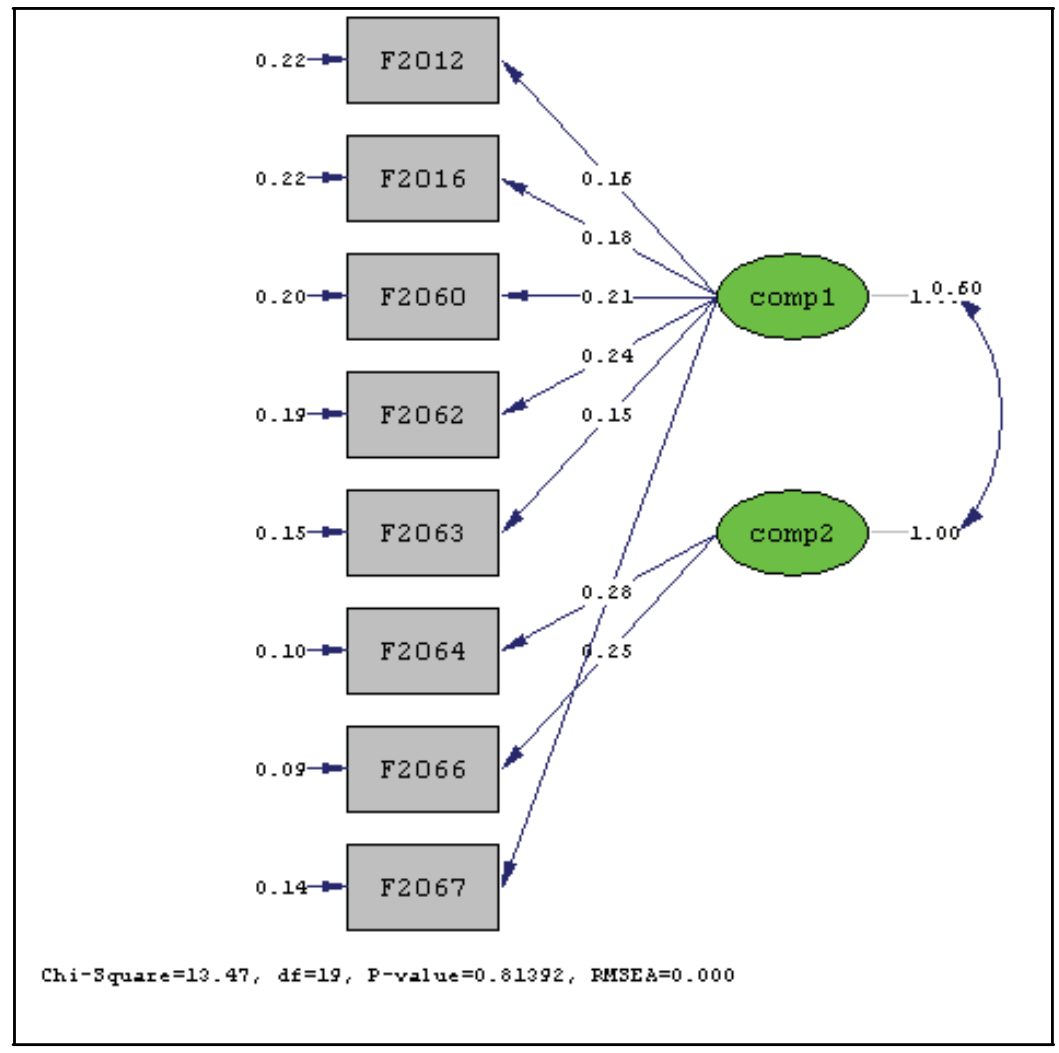

Figure 3: A measurement model improved by adding a skill.

The figure also indicates a correlation between the latent variables of value +0.60 , which attests to the proximity of the two skills. Furthermore, all the relations represented in the figure are significant. The new configuration thus obtained needs to be interpreted. Items 64 and 66 appear to measure a particular skill indicating the ability to spell nouns in the plural correctly: 'boys' (garçons) and 'girls' (filles). The six other items (12, 16, 60, 62, 63 and 67) appear to measure a different skill. A rigorous interpretation of these correlations requires the use of a range of theoretical resources. Indeed, the results obtained by pupils in the items of the first group appear to depend on different types of ability: spelling, memory, concentration...The measurement models applied to all the groups of items resulted in the identification of 63 latent variables at the start of CE2 (Morlaix \& Suchaut, 2006). The analysis of latent variables thus produced a reshuffle of skills at the start of CE2. 27 of the 63 variables 
thus highlighted (or 43\%) correspond (though often only partially) to groups of items already identified in national tests. The relation between the skills assessed in the evaluations and the latent variables is still imperfect since only 5 variables are exactly correlated with the skills measured in national tests (only Maths exercises). The same analysis of latent variables was carried out on tests at the start of $C P$ and at the start of 6ème.

The main advantage of identifying skills based on an analysis of latent variables is that it removes the conventional methods of classifying skills assessed in national tests by identifying groups of items that cannot be identified by adopting a disciplinary or subject approach. The virtue of this method is that it helps to reconstruct pupils' skills. The assumption is that some skills are crucial for providing a satisfactory account of learning. An approach based on the analysis of correlations between items helps to define skills in an alternative way, either by establishing connections between items based on different exercises or disciplines, or by consolidating and thus refining certain skills already assessed in national tests.

The activation of skills through the use of structural models serves to highlight the interdependence of the various skills identified, and clarifies the way in which success at school is stimulated at a given point in the learning process. Besides providing a useful cross-curricular analytical approach, this methodology fosters a longitudinal perspective by identifying the skills required for the acquisition of other skills, and by isolating those skills which constitute essential prerequisites for success at school. The cross-disciplinary construction of skills and the dynamics of learning are the object of the final section of this study.

\section{What are the implications of these findings for future research in education?}

The empirical redefinition of skills acquired by pupils at primary level suggests a dual analytical approach: cross-disciplinary on the one hand, longitudinal on the other. The first approach helps to identify the hierarchical and pyramidal structure of skills, especially at primary school. Thus, certain skills cannot be acquired if pupils have not already acquired other skills. For example, at the start of cycle III, subtraction figures at the top of the hierarchy, and cannot be mastered without the acquisition of other skills in a variety of areas (such as addition or the transformation of text, or an ability for mental arithmetic). Conversely, the base of the pyramid tends to include crossdisciplinary skills relating to an ability for sustained concentration, which the weakest pupils often struggle to acquire.

The initial results concerning the cross-disciplinary nature of early learning require an analysis of the evolution of relevant skills over time. From a longitudinal perspective, the skills acquired by pupils are built up over a period of several years. The main principles governing this evolution need to be identified. A dual phenomenon may 
be observed in the process of learning: diversification on the one hand, consolidation of the relations between acquired skills on the other, with all the consequences that such factors entail for potential success or failure at primary level. To a certain extent, success or failure gradually become more coherent over time and thus limit the possibility that some pupils failing in particular areas may compensate this weakness through success in other areas. These findings are the product of an analysis of the 1997 panel of the French Ministry of Education. They help to identify temporal connections between the skills developed by pupils throughout their primary school education, via a global figure representing the structure of acquired skills (see figure 4).

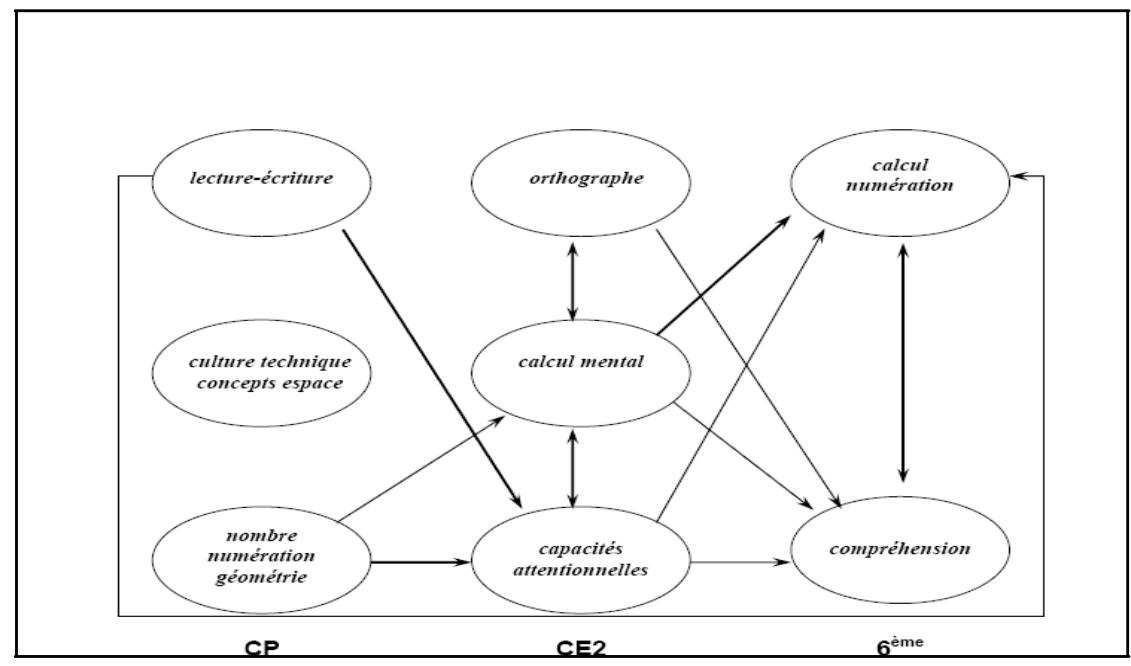

Figure 4: The structure of skills developed by pupils at primary level (Morlaix, 2007).

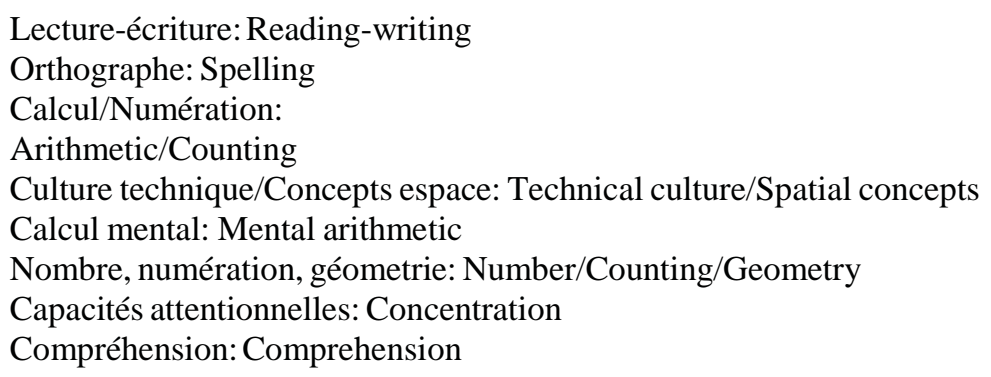

Figure 4 illustrates the statistical connections between different aspects of learning from the first year of primary school up to the first year of secondary school. The connections between groups of skills, represented on the graph by different arrows, highlight the dynamics of the learning process at primary level. The width of the arrows indicates the intensity of the statistical relations. This figure present the structural model, made with LSIREL. Without entering into the details of the complex analysis of connections between groups of skills, I suggest a broad outline of the relational structure illustrated by the graph.

At the start of $C P$, the learning process is primarily structured around three types of skill. The first group includes linguistic skills (oral comprehension, phonological 
exercises, morphology and syntax, writing) and concepts related to time, and covers the majority of skills in reading and writing. The second group includes spatial concepts and skills in technical culture. The exercises used to evaluate these two areas require a knowledge of notions, vocabulary, objects and situations commonly encountered in everyday life. The third and final group includes skills related to a knowledge of numbers, numerical activities and geometry. At the start of cycle III (CE2), the three categories defined above (mental arithmetic, spelling and concentration) constitute the main focus of learning. At the start of 6ème the skills acquired by pupils are mainly structured around two categories. The first category includes numerical abilities and arithmetic (especially mental arithmetic).

The second category includes a group of skills largely focused on reading comprehension.

An initial observation concerns the independence of some skills (technical culture and concepts relating to space) at the start of CP. In fact, both dimensions require the use of an essentially declarative form of knowledge rather than the application of actual skills. What is mainly involved is a general knowledge of vocabulary typically associated with a child's environment (recognition of technical objects, knowledge of terms relating to spatial orientation). A second observation concerns the interdependence of skills in the different areas assessed throughout a child's educational career. The different groups of skills were observed to display close connections reaching beyond traditional disciplinary boundaries (French and Maths). For example, skills in mental arithmetic in CE2 are connected with comprehension skills at the start of 6ème. Likewise, skills in numerical arithmetic acquired in $C P$ are closely connected with an ability for sustained concentration at the start of CE2. The third (and from my perspective most fundamental) observation concerns the emergence of a temporal structure governing the acquisition of skills throughout primary education. The strongest correlations (symbolized by the thickest arrows) highlight relations of dependence between different aspects of learning, which shows that the extent to which certain skills are acquired at the start of CP has an impact on the acquisition of other skills in later years. The use of structural models serves to highlight the interdependence of the various skills identified, and to prove the relation between different skills. In other words, the key skills at the start of secondary school are partly given by earlier skills have been acquired and mastered. More precisely, skills in written expression and numbers at the end of nursery school determine the ability for sustained concentration at the start of cycle III (CE2). This ability for sustained concentration is itself connected with skills in mental arithmetic, which in turn will tend to determine the acquisition of future skills in numerical tasks and arithmetic at the start of secondary school. Numerical and arithmetical skills will have an indirect impact on the development of comprehension skills, a crucial factor accounting for potential success or failure at secondary level. 
The identification of skills that represent a prerequisite for a successful educational career requires a specification of the various factors that are liable to stimulate the development of these skills, and to open the metaphorical 'black box' of the teachinglearning process. Because success at school may be construed as a cumulative process involving the structured acquisition of skills, I examined the nature of the skills developed by a successful pupil. Ultimately, this inquiry helped to identify the factors that condition this process. The variations observed in the results and in the kinds of skills effectively acquired are determined by the intermediary mechanisms of information treatment activated by pupils throughout the learning process. This hypothesis broadens the perspective generally adopted in the process- product paradigm, by focusing on 'the implicit human processes that come between pedagogical stimuli and the results of the learning process' (Levie \& Dickie, 1973, quoted in Doyle, 1978). Within the paradigm of mediating processes, in order to improve the results of learning, i.e. to stimulate the development of key skills, we need to observe what pupils effectively do in order to learn and acquire key skills. Recent work carried out in conjunction with educational psychologists (Barouillet, Camos, Morlaix \& Suchaut, 2008) highlighted the connections between the skills developed by pupils and their intrinsic characteristics, especially pupils’ cognitive abilities.

Some skills, such as the ability to carry out mental arithmetic (which, as noted above, plays a key role in the learning process), are closely connected with cognitive abilities. The kinds of cognitive ability highlighted in recent research relate specifically to work memory. The connection between these intermediary variables (cognitive abilities) and the results of learning (acquired skills) requires an investigation of the specific conditions of teaching (pedagogical practices, teachers' behaviour, pedagogical teams, etc.) that might profitably be devised to stimulate the development of certain cognitive abilities and, beyond these, the acquisition of skills required for a successful educational career. My current research does not focus particularly on these latter issues, although some of these points may provide fruitful avenues for future work in the field. My recent work has been rather more focused on the kinds of pedagogical practices of time management used by primary school teachers (Morlaix, 2000, 2006). The variability of teacher practices entails a number of consequences for the disparities observed between standards of learning in different pupils. This research tends to highlight a connection between time management in class and the development of a range of skills, abilities and aptitudes.

\section{Conclusion}

The initial results outlined above call for an in-depth analysis requiring the use of learning psychology to extend the findings of this research. There are clearly a number of interesting avenues that might be explored in future inquiries at primary level. The analyses outlined in this paper tend to demonstrate that pupils are better equipped at the start of secondary school if they have acquired significant skills at 
nursery school.

Perhaps we are now in a better position to understand the complexity and depth of the issue of skills in education, especially if we refer to distinct disciplinary fields that share a common goal, i.e. the improvement of our understanding of the factors that condition success at school. Methodological borrowings from a variety of disciplines, including economics, sociology and psychology, help to refine our understanding of the genesis of skill acquisitions and their evolution throughout a child's educational career. The issue raised by the consideration of the concept of skills is a very recent development in educational research, and suggests a number of promising avenues for future research in the field. It also suggests recommendations for educational policy related to pedagogical practices and the definition of curricula in terms of structure and content.

\section{Bibliography}

Aisch-Van Vaerenbergh, AM. (1997). Modèles statistiques et inférences causales: analyse des structures de covariances avec LISREL, Faut-il chercher aux causes une raison? L'explication causale en sciences humaines, Aish-Vaerenbergh, AM. et al., collection sciences-histoire-philosophie, 106-130.

Allal, L. (1999). Acquisitions et évaluation des compétences en situation. Dolz, J. et Ollagnier, E. L'énigme de la compétence en éducation (Bruxelles: De Boeck), 75-95.

Bacher, F. (1987). Les modèles structuraux en psychologie. Présentation d'un modèle LISREL. Première partie. Le travail humain, tome 50, 4, 347-370.

Barrouillet, P., Camos, V., Morlaix, S., Suchaut, B. (2008), 'Progressions scolaires, mémoire de travail et origine sociale: quels liens à l'école élémentaire?' Revue Française de Pédagogie, 162, 5-14.

Crahay,M. (2006). 'Dangers, incertitudes et incomplétude de la logique de la compétence en éducation’, Revue Française de Pédagogie, 154, 97-110

De Landsheere, G. (1971, 1992). Evaluation continue et examens. Précis de docimologie. Bruxelles: éditions Labor. Paris: Fernand Nathan.

De Landsheere, G. (1979). Dictionnaire de la recherche en éducation. Paris: PUF. Desmet, H., Pourtois, JP. (1997). Parents, agents de développement, Les familles et l'école -Apports de la recherche, points de vue de praticiens. Les dossiers d'éducation et formation, 101, 49-68. 
Doyle, W. (1978). 'Paradigms for Research on Teacher Effectiveness', Review of Research in Education, vol.5, 163-1983.

Duru-Bellat, M. (1995). 'Filles et garçons à l'école, approches psychologiques et psycho-sociales’, Revue Française de Pédagogie, 110. 75-109.

Duru-Bellat, M., Mons, N., Suchaut, B. (2004). 'Caractéristiques des systèmes éducatifs et compétences des jeunes de 15ans. L’éclairage des comparaisons entre pays’. Les Cahiers de l'IREDU, 66.

Joreskog, K., Sorbom, D. (1982). 'Recent Developments in Structural Equation Modeling'. Journal of Marketing Research, XIX.

Joreskog K., Van Tillo (1973). LISREL : A General Computer Program for Estimating a Linear Structural Equation System Involving Multiple Indicators of Unmeasured Variables. Research Report 73-5. Department of Statistics, Uppsala University, Uppsala Sweden.

Le Boterf, G. (1998). L’ingénierie des compétences, Paris: Ed d’organisation.

Leclerq, D., Nicaise, J., Demeuse, M. (2004).Docimologie critique: des difficultés de noter des copies et d'attribuer des notes aux élèves. Introduction aux théories et aux méthodes de la mesure en sciences psychologiques et en sciences de l'éducation. Liège: Les Editions de l’Université de Liège, 273-278.

Mandon, N. (1990).Analyse des emplois et gestion anticipée des compétences, CEREQ, Bref, 57.

Ministry of Education (1998). Observation à l'entrée au CP des élèves du panel 1997, Note d’information de la Direction de la Prospective et du développement, 98- 40, 6p.

Ministry of Education (2002). Note de service 2002-105 du 30.04.2002, B.O. N¹9 du 9 mai 2002.

Merle, P. (1996). Les recherches sur les notations des élèves : quelles conséquences en termes d'action sociale? Les dossiers Education et Formation, 53, 7-18.

Merle, P. (1998). Sociologie de l'évaluation scolaire, Paris: PUF.

Morlaix, S. (2000). Rechercher une meilleure répartition du temps en primaire pour favoriser l'insertion au collège. Revue Française de Pédagogie, 130, 121-131.

Morlaix, S. (2002). L'apport de l'analyse en structure de covariances dans les sciences 
sociales: exemple d'application à l'économie de l'éducation. L'Orientation Scolaire et Professionnelle, 31/1, 117-138.

Morlaix, S. (2006). Quel coût d'opportunité dans l'utilisation du temps scolaire ? Réflexion sur l'efficacité du temps dans le processus éducatif. Revue Administration et Education, 01/2006, 107-115.

Morlaix, S. (2006). Evolution et structure des compétences des élèves à l'école élémentaire et au collège. Une analyse empirique des évaluations nationales. En collaboration avec B. Suchaut. Rapport pour l'IRES (Institut de Recherches Economiques et sociales, 312p.

Morlaix, S. (2007). Identifier et évaluer les compétences dans le système éducatif: quels apports pour la recherche en éducation? Rapport d'HDR. Dijon, 174p.

Nias, D., Wilson, G. (1970). Love’s mysteries, Fontana. OECD (2001), Knowledge and kills For Life.

Perrenoud, P. (1995), La fabrication de l'excellence scolaire: du curriculum aux pratiques d'évaluation. Genève: Droz

Reuchlin, M. (1992). Introduction à la recherche en psychologie. Nathan Université.

Stroobants, M. (1998). Former et évaluer des compétences: des objectifs contradictoires? Bourdoncle, R. et Demailly, L. (éds.), Les professions de l'éducation et de la formation, Villeneuve d’Ascq: Presses Universitaires du Septentrion, 215- 224.

Vrignaud, P. (2006). La mesure de la littéracie dans PISA : la méthodologie était la réponse, mais quelle était la question? Revue Française de Pédagogie, 157, 27-41. 